\title{
Barriers in transition from pediatrics to adult medicine in sickle cell anemia
}

Jeffrey D Lebensburger

Christina J Bemrich-Stolz

Thomas H Howard

Department of Pediatrics, University of Alabama at Birmingham,

Birmingham, AL, USA.
Correspondence: Jeffrey Lebensburger 1600 7th Ave S, ACC5 I2, Birmingham, AL 35233, AL, USA

$\mathrm{Tel}+\mathrm{I} 2059399285$

Fax + I 205975 I94I

Email jlebensburger@peds.uab.edu
This article was published in the following Dove Press journal:

Journal of Blood Medicine

18 September 2012

Number of times this article has been viewed
Abstract: Transition of care from pediatric to adult providers is an essential step in the care of young adults with sickle cell anemia. Transition programs should be developed by individual institutions to systematically enhance the transition process for their patients. Prior to transfer, patients must be educated about their disease and personal medical history and develop skill sets required to navigate the adult health care setting. The objective of this literature review is to identify key concepts associated with transition of care for patients with sickle cell anemia. First, transition programs should be developed so that education about transition can begin at an early age. The readiness of patients and families should be assessed and education tailored to meet individual patient needs. Finally, the emotions and fears about transition should be recognized and addressed prior to transition.

Keywords: anemia, sickle cell, transition to adult care, health transition, adult care

\section{Introduction}

With improved comprehensive medical care, children with many congenital, genetic, and pediatric-onset disorders including cystic fibrosis, spina bifida, and congenital heart disease have experienced increased rates of survival into adulthood. ${ }^{1-3}$ This increase in survival is mirrored for patients with sickle cell anemia as recent data suggests that $93 \%$ of children born with sickle cell disease will live to 18 years old. ${ }^{4}$ As adolescents and young adult patients with chronic diseases age, their care is transferred to new adult health care providers and facilities.

While survival to adulthood is increased, many patients with chronic childhood illness, including patients with sickle cell anemia, experience an increase in disease complications and need for health care utilization during the time of transition..$^{5-8}$ In a review of health care utilization in eight US states from inpatient and emergency department databases, young adults with sickle cell anemia (18-30 years) demonstrated a very high need for hospital-based care. ${ }^{6}$ Young adults have greater than two times the amount of emergency room visits per year than those patients aged 10-17 years (1.59 versus $0.68)$ or adults aged $31-45$ (1.59 versus 1.29$)$. In addition, these patients have more inpatient stays than either adolescent (10-17 years) or older patients (31-45 years). Finally, young adult patients demonstrate the highest percent of frequent acute care visits (defined as $>10$ acute care visits/year) and return to acute care within 14 days. This trend towards increased health care utilization was further demonstrated in a 10-year evaluation of hospital admissions. ${ }^{9}$ A large cohort of 940 patients with sickle cell anemia demonstrates the medical vulnerability of young adults with sickle cell 
anemia. ${ }^{10}$ Within that cohort of pediatric sickle cell patients, all seven deaths occurred in patients between the ages of 18 and 23 years. Six of the seven deaths occurred within 2 years of being transitioned to an adult care provider. Together, this data strongly suggests that patients in the age of transition care are at risk for increased morbidity and mortality from their disease. The need for a strong transition program to enhance patient education about their disease and health maintenance cannot be understated.

This literature review focuses on describing the status of current sickle cell transition programs as well as areas important to transition success, including assessing patients' emotions and readiness for transition. Several limitations to transition programs cited in the literature could be addressed using these published models of transition care. Since transition requires a change in health behavior, an additional objective of this literature review is to explore theories of behavioral change that are required for a successful transition. Finally, we recommend specific interventions and future research opportunities to enhance transition programs during this time of increased medical vulnerability for young adults with sickle cell anemia.

\section{Transition programs}

Transition for young people with chronic health conditions is described by the Society for Adolescent Medicine as the "purposeful, planned and timely transition from child and family-centered pediatric health care to patient-centered adult-oriented health care,"11 the goal of which is "to optimize health and to facilitate each young person's attaining his or her maximum potential."12 This goal makes clear that transition should not be viewed as a simple transfer of medical care, but rather as a process wherein adolescents and young adults should be guided towards engagement in their medical care as well as increasingly adopting "adult roles and functioning." 13 A failure of programs to appropriately transition patients to an adult-oriented health care system likely plays a role in the medical vulnerability experienced by this patient population.

The importance of implementing a comprehensive plan to transition patients with chronic diseases is widely recognized. ${ }^{12}$ The recently developed quality-of-care indicators for children with sickle cell anemia include two care indicators that focused on the importance of creating a systematic plan for transition of care. ${ }^{14}$ The expert panel recommended (1) a transition plan that includes a written summary of the medical history, and (2) counseling for adolescent patients regarding the transition process. To emphasize the importance of the transition program for the quality of care for patients with sickle cell anemia, both indicators received a score of 8.5 out of 9 . This high score is defined as very important, and implementation of these indicators could result in a large positive impact for the patients to improve the quality of their lives and/or health outcomes.

Despite the value placed on developing and implementing a successful transition program, sickle cell centers have historically been lacking in transition care. In one large Midwestern city with three pediatric centers, no sickle cell program had a formalized transition of care plan in place. ${ }^{15}$ The lack of a transition plan may have directly affected the transition experience of 18 young adults with sickle cell in this study. Eleven of the 18 patients interviewed had no transition preparation; the additional seven patients had limited preparation that included a one-time discussion call to the adult care provider. An additional implication of not having a defined systematic transition plan is that patients may reach the age of transition without proper transition education. In this survey, five of the seven patients that had been transferred for age had no transition planning. It could be expected that a defined transition plan could improve the experience for patients in this city. From a national perspective, a survey of major sickle cell centers in the United States was conducted in which 30 of 45 identified centers participated. The survey focused on self-evaluation of transition programs. The most common transition plan $(72 \%)$ used by these centers was to have a planned transition discussion with adult care providers. ${ }^{16}$ In another very large survey of sickle cell providers, $67 \%$ of all providers provided at least one mechanism to demonstrate transition, with the highest demonstration of a transition plan provided by nurse practitioners $(86 \%){ }^{17}$

For those centers that have a defined transition program, an important component of their plan should include an outcomes assessment measure. In one survey, only $54 \%$ of centers evaluate their transition program and only $39 \%$ assess patient satisfaction with transition planning. ${ }^{16}$ These sickle cell centers recognized that they could improve their programs by rating their overall assessment of their transition plan as satisfactory (3.2 out of 5). Despite the low frequency of executing a transition plan, one survey identified that $89 \%$ of providers believed that a systematic transition process was needed. ${ }^{18}$ The providers believed that transition education should include patients seeing providers independently of their parents, encouraging the patient to accept more responsibility, making the patient more financially responsible, and having family conferences to discuss transition. 
A major barrier for sickle cell transition programs in several cities is the ability to identify an adult provider with expertise and interest in serving this population. In a recent survey of leading pediatric sickle cell centers, the most difficult aspect of transition was identifying an adult provider. ${ }^{16}$ Only $60 \%$ of these centers can transition their patients to an adult hematologist specializing in sickle cell anemia. This disparity in adult sickle cell health care providers is exaggerated for patients living in rural communities. ${ }^{17}$ Without local providers with expertise in sickle cell anemia, many patients are transferred to a general internist for their adult care. Unfortunately, one third of general internists surveyed express comfort in being the primary care provider for patients with sickle cell anemia. ${ }^{18}$ In addition, the majority of internists believed that they should not assume primary care responsibility for this patient population. The literature search did not identify strategies or programs that enhanced sickle cell training of primary care adult providers that participate in care of patients undergoing transition.

\section{Models to improve transition programs}

The recommendation for transition of young adults must expand beyond the concept of creating a transfer summary and discussing each patient at a transition meeting. While each institution has unique issues associated with developing and revising transition programs, models have been developed to assist in the global design of a transition program. In 2011, a call to action to improve health care transitions from adolescence to adulthood was issued jointly by the American Academies of Pediatrics and Family Physicians and the American College of Physicians..$^{19}$ In this report, an algorithm is suggested to enhance transition programs. The first step in the algorithm is to discuss office transition policy with youth and parents. This step is vital to introduce the patient and family to transition, a concept that may not be obvious to all adolescent patients..$^{20}$ Additionally, it requires that the sickle cell medical team has a transition plan established. The report recommends that the minimum requirement of a transition policy include defining the expected age of transfer (recommended as 12 years or older), as well as the defined responsibilities for all stakeholders during transition (patient, physician, and caregiver). The second step involves initial discussion of the transition plan. The report recommends utilizing readiness tools to assess a patient's ability to participate in transition education. The third step involves a reassessment of the general transition plan, in which practitioners review the response to transition and assess patient readiness so that they can tailor the specific transition plan for that patient and family based on individual needs. Once the reassessment has been completed, the finalized and patient-centered transition plan can be implemented in step four. The transition plan should include direct communication between pediatric and adult providers, development of a portable medical summary, and medication reconciliation.

A second model for institutions to consider in designing or revising their transition program was developed by the Center for Medical Home Improvement, which supports enabling successful transition. ${ }^{21}$ The Center for Medical Home Improvement focuses on educating consumers, families and medical professionals about transition best practices, establishing patient registries and monitoring individual health care transitions, developing explicit action plans including emergency response, and assuring direct communication among the consumer, families, pediatric and adult primary care professionals. The six core elements of transition are: (1) transition policy; (2) transitioning youth registry; (3) transition preparation; (4) transition planning; (5) transition and transfer of care; and (6) transition completion. A unique aspect of this plan is step 2 in which patients are registered into a registry and followed over time, recording the dates on which the six core elements of transition were accomplished..$^{21}$ Both the American Academy of Pediatrics (http://www.AAP.org) and the National Center for Medical Home Implementation (http://www.gottransition.org) have excellent resources for institutions to utilize when developing or revising their transition programs.

\section{Recommendations}

Institutions should develop a transition program that is appropriate for their unique clinical and social environments. Different published models for transition can be utilized for institutions to rapidly develop or revise their transition program. Transition should be initiated early so that a complete transition education program can be completed by all patients. Sickle cell anemia is a chronic disease with patients experiencing frequent clinic visits. The frequency of both well and sick clinic visits allows providers to introduce and educate patients and caregivers over several years about transition. During well visits, areas of transition that can be addressed include introduction of transition, discussion of health insurance, guardianship, disability, and work experiences. By utilizing a patient-readiness assessment (described later), the visits can be tailored so that these complex topics are introduced at an appropriate time point. 
During sick visits/hospitalizations and when patient health improves, providers should educate the patient on how to obtain medical care when a similar illness occurs in the adult setting. Finally, individual and program feedback is vital so that the transition plan can be evaluated and revised to maximize efficiency for the institution.

\section{Patient readiness}

\section{Background}

The first step in transition of care from a pediatric to an adult provider involves introducing a patient and his/her family or guardian to the concept of transition. While this is the obvious first step, it is often a difficult and avoided topic for pediatric providers who do not have a transition plan in place and/or have developed strong relationships with patients and families. From the adolescent perspective, patients must first accept the often difficult concept of transitioning to a different doctor and care setting. During the initial discussion of transition, the patient will be asked to participate in a behavioral change with which they may not yet be comfortable. The patient must begin to accept responsibility for his/her own health care from the parent or health care guardian. The importance of assessing readiness is vital, as education about transition will be maximized after the patient has initiated this behavioral change and accepted the concept of transition of care.

Patient readiness is often assessed in the literature by determining whether a patient understands his/her own medical history, how they feel about transition, and where he/she will receive medical care. ${ }^{22,23,25}$ However, scant literature exists on strategies to engage patients in transition and enhance a patient's ability to initiate this behavioral change. Without literature identifying successful strategies to enhance patient readiness in sickle cell transition, behavioral theories can be utilized to facilitate a program's understanding of the change that a patient must experience. The transtheoretical model and stages of change provide a model by which physicians and medical teams could assess patient readiness. Once a patient is ready to accept transition of care to an adult provider, the pediatric team can effectively provide education to the patient.

The five stages of change in the transtheoretical model include precontemplation, contemplation, preparation, action, and maintenance, and describe the transition from a patient who has not yet considered transition to adult provider to an adolescent that fully accepts care for their own disease (Table 1). ${ }^{24}$ Precontemplation is the earliest stage, in which a patient has no intention to understand and accept
Table I Stages of change ${ }^{24}$

\begin{tabular}{ll}
\hline Stage & Relevance to transition care \\
\hline Precontemplation & $\begin{array}{l}\text { Introduce the concept and time in which } \\
\text { transition will occur. Understand that the } \\
\text { patient may develop negative feelings toward } \\
\text { the process, including abandonment. }\end{array}$ \\
& $\begin{array}{l}\text { Explain the plan for transition and education } \\
\text { goals for the patient. }\end{array}$ \\
Preparation & Institute transition care plan. \\
Action & Complete transition care education. \\
Maintenance & Self-efficacy.
\end{tabular}

responsibility for their own care. The precontemplation stage represents the majority of teenage patients with sickle cell anemia. For patients in the precontemplation stage, providers should place their focus on introducing the topic of transition and educating the patient that, at a specified age or time, their care will be transitioned to an adult provider. For many patients, the concept of transition care is not understood and the introduction of transition evokes negative feelings. The main goal of transition education involves patient education; however, this education may be delayed during the precontemplation stage. Provider attempts to educate children on their disease history is important, but may not be as effective as a later stage. Contemplation is the second stage, in which a patient begins to consider a strategy for accepting the need for transition care. During this stage, providers should begin to describe the process of transition of care so that the patient can begin to decide on a plan of how they would like to proceed with the behavioral change of accepting responsibility of their own care. Preparation is the stage in which a patient prepares to make the behavioral change within 30 days and, to some degree, has initiated their plan to accept responsibility for their own care. At this point, individual providers should institute their active phases of transition of care education. It is important that individual providers/institutions have a plan in place to effectively transition their patients. Action is the stage in which a patient has accepted transition care and has been working on understanding their medical history for less than six months. Concepts vital to the action phase of transition care include understanding medical history, identifying adult care providers, educating on insurance issues, and developing a care plan for disease complications. Finally, maintenance is the stage in which the patient continues to accept responsibility for their own care. This stage may occur after transition to adult providers. Interestingly, patient factors associated with the development of self-efficacy during transition is similar in different countries. ${ }^{26}$ 


\section{Implementation of a plan to assess readiness}

The assessment of readiness in patients with sickle cell anemia has been explored by McPherson et al, who evaluated five components of readiness: ${ }^{25}$ (1) amount of prior thought about transition; (2) knowledge about transition (including to which hospital they will be transferred, medical history to convey, how to make appointments, if insurance would be accepted); (3) interest in learning about transition; (4) anticipated difficulties in transition; and (5) perceived importance of transition. Participant responses reflected their strong desire to be transitioned to an adult physician with expertise in sickle cell anemia yet they had little actual knowledge about the transition process. Seventy-nine percent of participants reported having little or no thought about transition, the first step required to undergo a behavioral change. It could be speculated that a defined transition plan could overcome this barrier to transition by specifically introducing transition at an earlier age (around 12 years) so that these patients could begin contemplation prior to the time of transfer. Patients with sickle cell anemia also often develop brain hypoxia and injuries that decrease their cognitive abilities..$^{27-31}$ Therefore, an additional tool to assess patient readiness could include a neuropsychological assessment allowing transition education to be targeted at an appropriate education level..$^{32,33}$

While transition readiness is often focused on the patient, providers should also understand the degree of parental commitment to transition. The level of parental involvement through the pediatric years may have an inverse relationship on patient readiness. Patients with poor family relationships have been found to be most likely to be prepared for transition, likely as the result of prior experiences in which the patient felt the need to care for him/herself without significant parental involvement. ${ }^{34}$ For patients with strong family relationships, pediatric providers should encourage patients to accept more responsibility for their own care. Suggestions to enhance patient self-efficacy should include seeing the patient (at least for a portion of the exam) without their parents, making the patient more financially responsible for payments, medication pick-up, etc. ${ }^{17}$ The pediatric provider should work to develop self efficacy in their patient, whereby the patient can develop the confidence required to change the focus of responsibility for their medical care from their parent or provider to their self. ${ }^{15}$

While the patient must develop independence of care, parents or guardians should be included in transition education, especially since the immediate years after transition can be associated with life-threatening events. ${ }^{4}$ Parents should be encouraged to maintain an active role in assisting their child's evaluation of his/her active disease status and promote healthy lifestyle choices as an adult. In addition, parents should be educated about the adult care setting so that they can assist their young adult to navigate the new health care experience. Depending on the state, young adults in the US might still be included on a parent's health insurance, which may improve patient access to providers. In these situations, changes in parent insurance should be explained to their child so that lapses in health insurance do not occur. The transition period should promote self-efficacy but should not exclude parental involvement.

\section{Recommendations}

Providers and institutions for pediatric patients with sickle cell anemia should assess readiness as part of their transition care plan. This assessment will allow transition programs to be individualized for each patient. Family members should be included in transition so that they can provide additional support for young adults after transition has occurred.

\section{Patient emotions during transition Patient beliefs}

Sickle cell disease can be associated with frequent, debilitating pain crises requiring hospitalization, and patients may become emotionally dependent on their pediatric provider. The level of dependence on their health care provider and comfort with the pediatric setting can create a variety of emotions for the patient undergoing transition. Without a defined transition plan that educates patients about transition over time, many patients are transferred based on age. ${ }^{15,16}$ An abrupt transfer can create a situation in which the emotions experienced by the patients are not adequately addressed, creating rapid turmoil and a negative situation in which adolescent patients feel forced into and unprepared for transition of care. ${ }^{23}$

Many interviews have identified several patient fears, including: (1) leaving the current provider; (2) establishing trust with a new provider; and (3) navigating a new health care system (Table 2) ${ }^{20,22,23,25,35-37}$ Several interviews have identified patient concern about having to create a new relationship and degree of trust with their adult provider. ${ }^{22,23,25}$ Since patients with sickle cell anemia may have had frequent medical and psychosocial issues addressed by their pediatric provider, many have strong concerns about their new provider understanding the intricacies of their disease complications. ${ }^{23}$ 
Table 2 Patient interview responses

\begin{tabular}{|c|c|}
\hline $\begin{array}{l}\text { Emotions of patient when introduced } \\
\text { to transition }\end{array}$ & Quotes from patient interviews about transition ${ }^{20}$ \\
\hline Leaving current provider & $\begin{array}{l}\text { "Why are you trying to send me over there. I've been knowing you since I was a little girl to now } \\
\text { and how could you. You know me, you know my daddy and my mamma." } \\
\text { "It's like someone pulled the rug out under me." }\end{array}$ \\
\hline Establishing trust with new provider & $\begin{array}{l}\text { "Who was going to be my doctor and was she going to be nice from the time when I come over?" } \\
\text { "I was worried what the new doctor would be like. How would he know how to take care of me } \\
\text { the way you guys would." }\end{array}$ \\
\hline Distrust of adult provider & $\begin{array}{l}\text { "People don't treat you with respect and kindness." } \\
\text { "I've had a problem with doctors trusting me with my medication, but I have to explain that it's } \\
\text { me in pain, I don't want to be in pain. I would be the last person to misuse my medications." } \\
\text { On adult ER setting: "We are going to treat her like every other sickle cell patient. We are going } \\
\text { to give her some drugs and kick her out the door." }\end{array}$ \\
\hline Navigating new health care system & $\begin{array}{l}\text { "How to get used to being over here instead of going to Children's. The different scenery." } \\
\text { "I was definitely concerned about switching because that's all I knew - Children's and the doctors } \\
\text { I was seeing there. I was definitely scared to move over to (the adult hospital)." }\end{array}$ \\
\hline
\end{tabular}

\section{Theories with which to address patient emotions}

A major emotion expressed by patients undergoing transition of care involves fear and stress. Therefore, to facilitate successful transition, a transition program should include a basic understanding of theories associated with stress and development of coping mechanisms. The transactional model of stress and coping starts with a patient's primary and secondary appraisal of the stressor, in this case the notification that they will be transitioned to a new provider and adult health care system. ${ }^{38}$ During this phase, patients evaluate the information and determine the level of stress associated with the transition process. The literature suggests that the notification of transition is associated with a negative stressor. After the initial and secondary appraisal of this stressor, coping efforts must begin. Two types of coping mechanism are frequently utilized by patients. Emotional regulation is one coping mechanism, by which patients begin to develop strategies to overcome the stressors. Patients may attempt to deny or avoid the subject of transition, vent their feelings of frustration to others, or seek social support from their family. Clinicians could intervene during this time to assist patients in reinterpreting a negative appraisal of the transition process. ${ }^{39}$ The literature supports positive response to transition when patients view transition to an adult provider as a logical next step in their life, allowing them to continue their natural experiences to pursue independence from their parents/guardians in several aspects of their lives. After transition has occurred, patients frequently remarked on how transition should have occurred earlier. ${ }^{20}$ Problem management is a second coping mechanism utilized by patients to actively seek strategies to overcome their stress. Patients have provided ample evidence of recommendations for relieving the stress, including being introduced to the new physician and visiting the adult hematology clinic prior to transfer of care, assistance with making first transition appointment, and peer referral to patients who have recently been transitioned..$^{22,23,25}$ Finally, many patients are skeptical about the process of transition to a new provider. The physicians could embrace this skepticism and use it as a means by which to teach the patient about differences in the culture of adult medicine. ${ }^{40}$ These recommendations should be integrated into an institution's policies regarding transition to adult care.

\section{Implementation of a plan to enhance patient emotions about transition}

Patients must be informed that there is a plan for transition of care from an early age. Early notification will allow time for physicians to address patient fears and redirect negative feelings about the process. One major fear for patients involves meeting a new physician. Based on institutional capabilities, physicians may establish a transition program in which they set up a transition clinic and in which the adult and pediatric physicians see the patient together. A second fear involves learning a new health care system. Part of the transition education may involve showing the patient the adult clinic prior to their first visit. This could be accomplished by the current medical team or a peer educator who has recently transferred to the adult program and who could provide the patient with a practical perspective on transition. Finally, patients often focus on the negativity of leaving the provider who cared for them as a child for a long time. The provider should redirect these negative feelings by focusing on the positive aspects of transition. An easy correlation for patients is to connect 
transition to an adult provider with their recent/pending graduation from school. As patients often are fighting for independence from parents at this time, physicians can focus on the positives of gaining independence from their parents for their medical care.

\section{Recommendations}

Physicians and parents should recognize the emotional distress associated with transition. By initiating transition early, the health care providers should have time to identify and address fears and concerns of the patients. Plans should be individualized so that interventions to reduce fears (meeting new physician, visiting new clinic) can be performed.

\section{Conclusion}

Transition from pediatric to adult care is a national problem for all chronic diseases. This problem is compounded for patients with sickle cell anemia who experience unique barriers during transition that lead to an increase in utilization of acute medical care facilities and a high rate of mortality from disease complications. Though it has been proposed that improving health education during transition of care may reduce morbidity from this disease, the current literature identifying barriers to transition of care from the stakeholder perspective is limited and not specific to sickle cell anemia. We propose three recommendations for future research in transition education:

1. The lack of specific knowledge regarding educational, institutional and sociocultural factors that impact transition in this population impedes the ability for practitioners to provide a user-centered approach to transition care. We recommend additional research to address barriers to transition from all involved stakeholders, including patients, sickle cell and emergency room physicians, social workers, and sickle cell advocacy groups.

2. Once a user-centered approach to transition is identified and implemented, evaluation of health outcomes associated with various transition programs should be implemented to determine how these programs are able to impact patients' morbidity, mortality, costs, and quality of life.

3. The lack of adult providers with expertise and who are comfortable caring for young adults with sickle cell anemia is a systematic barrier to creating a medical home for these patients. Transition research must incorporate development of strategies that promote an increase in provider expertise and commitment to care for these patients.

\section{Disclosure}

The authors report no conflicts of interest in this work.

\section{References}

1. Buzzetti R, Salvatore D, Baldo E, et al. An overview of international literature from cystic fibrosis registries: 1 . Mortality and survival studies in cystic fibrosis. J Cyst Fibros. 2009;8:229-237.

2. Wong LY, Paulozzi LJ. Survival of infants with spina bifida: a population study, 1979-1994. Paediatr Perinat Epidemiol. 2001;15: 374-378.

3. Moons P, Sluysmans T, De Wolf D, et al. Congenital heart disease in 111225 births in Belgium: birth prevalence, treatment and survival in the 21st century. Acta Paediatr. 2009;98:472-477.

4. Quinn CT, Rogers ZR, Buchanan GR. Survival of children with sickle cell disease. Blood. 2004;103:4023-4027.

5. Shankar SM, Arbogast PG, Mitchel E, Cooper WO, Wang WC, Griffin MR. Medical care utilization and mortality in sickle cell disease: a population-based study. Am J Hematol. 2005;80:262-270.

6. Brousseau DC, Owens PL, Mosso AL, Panepinto JA, Steiner CA. Acute care utilization and rehospitalizations for sickle cell disease. JAMA. 2010;303:1288-1294.

7. Hersh AO, Pang S, Curran ML, Milojevic DS, von Scheven E. The challenges of transferring chronic illness patients to adult care: reflections from pediatric and adult rheumatology at a US academic center. Pediatr Rheumatol Online J. 2009;7:13.

8. Nakhla M, Daneman D, To T, Paradis G, Guttmann A. Transition to adult care for youths with diabetes mellitus: findings from a Universal Health Care System. Pediatrics. 2009;124:e1134-e1141.

9. Dickerson AK, Klima J, Rhodes MM, O’Brien SH. Young adults with SCD in US children's hospitals: are they different from adolescents? Pediatr Blood Cancer. 2012;58:741-745.

10. Quinn CT, Rogers ZR, McCavit TL, Buchanan GR. Improved survival of children and adolescents with sickle cell disease. Blood. 2010;115: 3447-3452.

11. Blum RW, Garell D, Hodgman CH, et al. Transition from child-centered to adult health-care systems for adolescents with chronic conditions. A position paper of the Society for Adolescent Medicine. J Adolesc Health. 1993;14:570-576.

12. Rosen DS, Blum RW, Britto M, Sawyer SM, Siegel DM; Society for Adolescent Medicine. Transition to adult health care for adolescents and young adults with chronic conditions: position paper of the Society for Adolescent Medicine. J Adolesc Health. 2003;33:309-311.

13. American Academy of Pediatrics, American Academy of Family Physicians, American College of Physicians-American Society of Internal Medicine. A consensus statement on health care transitions for young adults with special health care needs. Pediatrics. 2002;110(6 Pt 2): 1304-1306.

14. Wang CJ, Kavanagh PL, Little AA, Holliman JB, Sprinz PG. Quality-of-care indicators for children with sickle cell disease. Pediatrics. 2011;128:484-493.

15. Wojciechowski EA, Hurtig A, Dorn L. A natural history study of adolescents and young adults with sickle cell disease as they transfer to adult care: a need for case management services. J Pediatr Nurs. 2002; 17:18-27.

16. Sobota A, Neufeld EJ, Sprinz P, Heeney MM. Transition from pediatric to adult care for sickle cell disease: results of a survey of pediatric providers. Am J Hematol. 2011;86:512-515.

17. Telfair J, Alexander LR, Loosier PS, Alleman-Velez PL, Simmons J. Providers' perspectives and beliefs regarding transition to adult care for adolescents with sickle cell disease. J Health Care Poor Underserved. 2004; $15: 443-461$

18. Okumura MJ, Heisler M, Davis MM, Cabana MD, Demonner S, Kerr EA. Comfort of general internists and general pediatricians in providing care for young adults with chronic illnesses of childhood. J Gen Intern Med. 2008;23:1621-1627. 
19. American Academy of Pediatrics; American Academy of Family Physicians; American College of Physicians; Transitions Clinical Report Authoring Group, Cooley WC, Sagerman PJ. Supporting the Health Care Transition From Adolescence to Adulthood in the Medical Home. Pediatrics. 2011;128:182-200.

20. Bemrich-Stolz CJ, Lebensburger JD, Halanych JH, Howard TH. Adult care experiences and barriers to transition in adult patients with sickle cell anemia. Blood. 2011;118:1364. http://abstracts.hematologylibrary. org/cgi/content/abstract/118/21/3155?maxtoshow=\&hits=10\&RESUL TFORMAT $=\&$ fulltext $=$ bemrich $\&$ searchid $=1 \&$ FIRSTINDEX $=0 \&$ volu me $=118 \&$ issue $=21 \&$ resourcetype $=$ HWCIT.

21. Six Core Elements of Health Care Transition. Retrieved August 13, 2012, from www.gottransition.org/6-core-elements. Accessed August $13,2012$.

22. van Staa AL, Jedeloo S, van Meeteren J, Latour JM. Crossing the transition chasm: experiences and recommendations for improving transitional care of young adults, parents and providers. Child Care Health Dev. 2011;37:821-832.

23. Tuchman LK, Slap GB, Britto MT. Transition to adult care: experiences and expectations of adolescents with a chronic illness. Child Care Health Dev. 2008;34:557-563.

24. Prochaska JO, Velicer WF. The transtheoretical model of health behavior change. Am J Health Promot 1997;12:38-48.

25. McPherson M, Thaniel L, Minniti CP. Transition of patients with sickle cell disease from pediatric to adult care: Assessing patient readiness. Pediatr Blood Cancer. 2009;52:838-841.

26. Anie KA, Telfair J; Sickle Cell Disease Transition Study Working Group. Multi-site study of transition in adolescents with sickle cell disease in the United Kingdom and the United States. Int J Adolesc Med Health. 2005; 17:169-178.

27. Hogan AM, Pit-ten Cate IM, Vargha-Khadem F, Prengler M, Kirkham FJ. Physiological correlates of intellectual function in children with sickle cell disease: hypoxaemia, hyperaemia and brain infarction. Dev Sci. 2006;9:379-387.

28. King A, Herron S, McKinstry R, et al. A multidisciplinary health care team's efforts to improve educational attainment in children with sicklecell anemia and cerebral infarcts. J Sch Health. 2006;76:33-37.
29. King AA, DeBaun MR, White DA. Need for cognitive rehabilitation for children with sickle cell disease and strokes. Expert Rev Neurother. 2008;8:291-296.

30. Watkins KE, Hewes DK, Connelly A, et al. Cognitive deficits associated with frontal-lobe infarction in children with sickle cell disease. Dev Med Child Neurol. 1998;40:536-543.

31. Kwiatkowski JL, Zimmerman RA, Pollock AN, et al. Silent infarcts in young children with sickle cell disease. Br J Haematol. 2009;146: 300-305.

32. Wills KE, Nelson SC, Hennessy J, et al. Transition planning for youth with sickle cell disease: embedding neuropsychological assessment into comprehensive care. Pediatrics. 2010;126 Suppl 3:S151-S159.

33. Daly B, Kral MC, Tarazi RA. The role of neuropsychological evaluation in pediatric sickle cell disease. Clin Neuropsychol. 2011;25: 903-925.

34. Newland JA. Factors influencing independence in adolescents with sickle cell disease. J Child Adolesc Psychiatr Nurs. 2008;21:177-185.

35. Telfair J, Myers J, Drezner S. Transfer as a component of the transition of adolescents with sickle cell disease to adult care: adolescent, adult, and parent perspectives. J Adolesc Health. 1994;15:558-565.

36. Smith GM, Lewis VR, Whitworth E, Gold DT, Thornburg CD. Growing up with sickle cell disease: a pilot study of a transition program for adolescents with sickle cell disease. J Pediatr Hematol Oncol. 2011;33: 379-382.

37. Hauser ES, Dorn L. Transitioning adolescents with sickle cell disease to adult-centered care. Pediatr Nurs. 1999;25:479-488.

38. Lazarus RS, Folkman S. Stress, Appraisal, and Coping. New York: Springer Publishing Company; 1984.

39. Lazarus RS. From psychological stress to the emotions: a history of changing outlooks. Annu Rev Psychol. 1993;44:1-21.

40. Rouse CM. Informing choice or teaching submission to medical authority: a case study of adolescent transitioning for sickle cell patients. Ethn Health. 2011;16:313-325.
Journal of Blood Medicine

\section{Publish your work in this journal}

The Journal of Blood Medicine is an international, peer-reviewed, open access, online journal publishing laboratory, experimental and clinical aspects of all topics pertaining to blood based medicine including but not limited to: Transfusion Medicine; Blood collection, Donor issues, Transmittable diseases, and Blood banking logistics; Immunohematology; Artificial and alternative

\section{Dovepress}

blood based therapeutics; Hematology; Biotechnology/nanotechnology of blood related medicine; Legal aspects of blood medicine; Historical perspectives. The manuscript management system is completely online and includes a very quick and fair peer-review system. Visit http://www.dovepress.com/ testimonials.php to read real quotes from published authors. 